\title{
Exploitation of the full potential of PSI data for subsidence monitoring
}

\author{
M. Crosetto ${ }^{1}$, N. Devanthéry ${ }^{1}$, M. Cuevas-González ${ }^{1}$, O. $_{\text {Monserrat }}{ }^{1}$, and B. Crippa ${ }^{2}$ \\ ${ }^{1}$ Centre Tecnològic de les Telecomunicacions de Catalunya (CTTC), Castelldefels, Barcelona, Spain \\ ${ }^{2}$ Department of Earth Sciences, University of Milan, Milan, Italy \\ Correspondence to: M. Crosetto (mcrosetto@cttc.cat) \\ Published: 12 November 2015
}

\begin{abstract}
Persistent Scatterer Interferometry (PSI) is a remote sensing technique used to measure and monitor land deformation from a stack of interferometric SAR images. The main products that can be derived using the PSI technique are the deformation maps and the time series of deformation. In this paper, an approach to apply the PSI technique to a stack of Sentinel-1 images is described. Moreover, the problems encountered during the processing are detailed and an explanation of how they were dealt with is provided. Finally, Sentinel-1 deformation maps and time series obtained over the metropolitan area of Mexico DF are shown.
\end{abstract}

\section{Introduction}

Satellite-based radar interferometry represents a powerful tool to detect and monitor ground deformation. For instance, successful land deformation estimates have demonstrated the potential of this technique for a wide range of applications related to landslides (Colesanti et al., 2003; Hilley et al., 2004; Bovenga et al., 2012), land subsidence caused by groundwater pumping (Tomás et al., 2005; Stramondo et al., 2007; Bell et al., 2008; Heleno et al., 2011) and mining (Colesanti et al., 2005; Jung et al., 2007), or urban monitoring (Crosetto et al., 2008; Vallone et al., 2008; Cigna et al., 2012).

This paper is focused on the application of Persistent Scatterer Interferometry (PSI; Ferretti et al., 2000, 2001) for land subsidence detection and measurement. Differential Interferometric Synthetic Aperture Radar (DInSAR) and PSI techniques have undergone a major development in the last two decades (Crosetto et al., 2015), mainly related to the progress accomplished through the exploitation of C-band data from ERS-1/2, Envisat and Radarsat. The data acquired by these satellites cover long periods of time, which is a key aspect to guarantee a long-term deformation monitoring. The advent of very high resolution X-band data in 2007 led to a major step forward in the PSI techniques (Crosetto et al., 2015), including the capability to generate a dense sampling of Persistent Scatterers (PSs), a higher sensitivity to small displace- ments and a remarkable quality improvement of the time series with respect to the C-band. Furthermore, a new significant improvement is expected to occur as a result of the data acquired by the C-band sensor onboard the Sentinel-1 satellite, launched on 3 April 2014. Sentinel-1 will improve the data acquisition performance with respect to previous sensors, especially for what concerns the area coverage, revisiting time and data throughput, considerably increasing the deformation monitoring potential of the PSI technique.

This article describes the first PSI processing experience of the authors with Sentinel-1 data by defining the processing strategy and illustrating the first results obtained over the metropolitan area of Mexico DF, i.e. the accumulated deformation map and the time series of deformation.

\section{Data processing}

The key steps of the procedure used to process the Sentinel-1 imagery are described in this section. The first stage of the processing is the generation of the interferograms. The key step of this stage is image coregistration, which in the case of Terrain Observation with Progressive Scan (TOPS) images (Prats-Iraola et al., 2012; Meta et al., 2010) requires a high accuracy. When this accuracy is not achieved, large linear terms appear in the interferograms. In this study, an approach that works burst-wise and does not require precise 
orbits is used, which causes an azimuth linear term in each interferogram. This linear term has been estimated imagewise and removed from the interferograms. To clean the linear term from the interferograms, a phase unwrapping using the Minimum Cost Flow method (Costantini, 1998; Costantini et al., 1999) was performed. This step has been executed over the interferograms multilooked 2 in azimuth and 10 in range in order to reduce the noise. Then, a direct integration, which consists in retrieving the image phases with respect to a given image, is done over the unwrapped interferograms. Finally, the linear planes have been estimated from the phase images and subsequently removed from the original interferograms.

Two key steps of the PSIG (PSI chain of the Geomatics Division of CTTC) procedure (Crosetto et al., 2011; Devanthéry et al., 2014) have been applied to derive the accumulated deformation map and the deformation time series: the so-called Cousin PSs (CPSs) selection and the $2+1$-D phase unwrapping. These two steps are briefly explained below:

- CPS selection: the aim of the CPS selection is to derive a set of PSs characterized by a moderate spatial phase variation to ensure a correct phase unwrapping and guarantee a uniform CPS coverage. This selection works at full resolution and is suitable to cover wide areas. It consists of a candidate CPSs selection step based on an iterative phase similitude criterion and a phase unwrapping consistency check. The procedure consists in an iterative search propagation criterion that starts with the selection of one or more seed PSs located on the ground, with no motion or thermal expansion and characterized by small noise. The candidate CPSs are those PS candidates that satisfy the condition:

$\left|\Delta \varphi_{i, \mathrm{SEED}}^{\mathrm{unw}}\right|_{90 \%}<\mathrm{Thr}$

where $\left|\Delta \varphi_{i, \mathrm{SEED}}^{\text {unw }}\right| 90 \%$ is the 90th percentile of the unwrapped phase differences between the seed and the $i$ th PS candidate over the minimum independent interferogram configuration network, and $\mathrm{Thr}$ is the phase difference threshold, which is defined as a function of the distance from the seed to account for the atmospheric effects.

$-2+1$-D phase unwrapping: this step is performed over the selected CPSs to derive the deformation measurements and some quality index tools of the estimations. It consists in a spatial 2-D phase unwrapping performed on each interferogram using the Minimum Cost Flow method (Costantini, 1998; Costantini et al., 1999), and a 1-D phase unwrapping performed pixel wise over the interferogram network. It uses an iterative Least Squares (LS) procedure (Baarda, 1968; Förstner, 1986; Björck, 1996), which exploits the integer nature of the unwrapping errors. It is based on the estimation of the following system of equations:

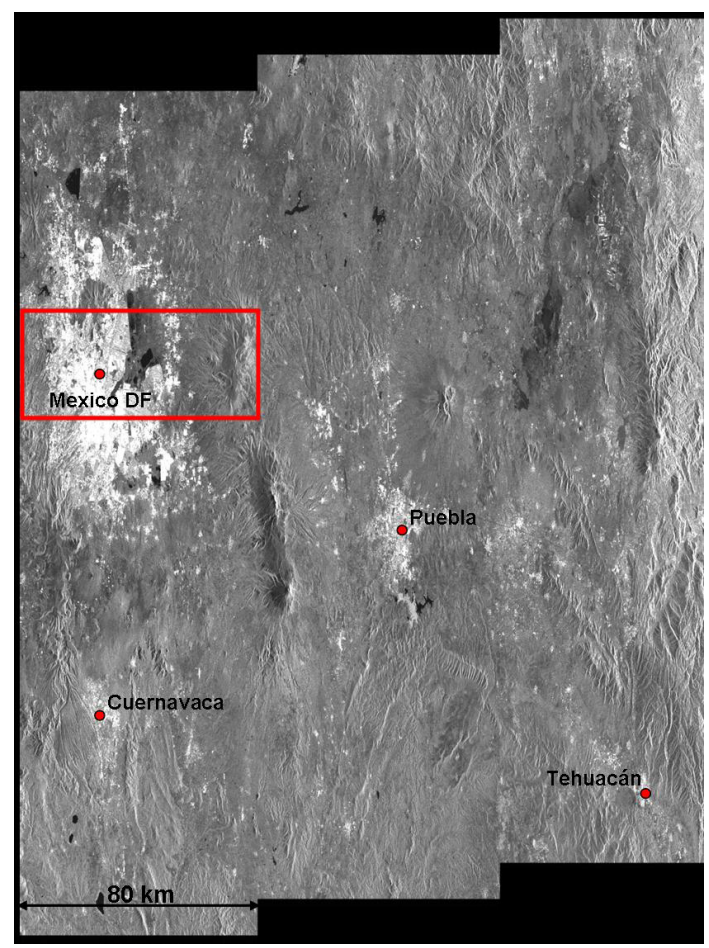

Figure 1. SAR amplitude of the Mexico dataset. Scene acquired by the Sentinel-1 satellite covering approximately 250 by $180 \mathrm{~km}$. The red square indicates the area processed using the PSI technique.

$$
\begin{aligned}
& \Delta \varphi_{\mathrm{MS}}=\widetilde{\varphi}_{\mathrm{S}}-\widetilde{\varphi}_{\mathrm{M}} \\
& \widetilde{\varphi}_{0}=0
\end{aligned}
$$

where $\Delta \varphi_{\mathrm{MS}}$ are the unwrapped interferometric phases (the observations), "S" and " $\mathrm{M}$ " are the slave and master images (the unknowns).

The system is solved by means of an iterative LS driven by two key parameters: the residuals $\hat{\varphi}_{\text {res }}$, which are the difference between the observations and estimated phases, and the redundancy of the network. If there is sufficient system redundancy, typically more than 10 interferograms per image, the procedure detects and corrects the unwrapping errors.

In this study, ten Interferometric Wide swath (IW) Single Look Complex (SLC) Sentinel-1 descending images spanning the period between October 2014 and January 2015 were used to derive the deformation map and time series.

\section{Results}

The results of the burst-wise procedure for the processing of Sentinel-1 data are illustrated in this section. A IW SLC Sentinel- 1 scene covers approximately $250 \times 180 \mathrm{~km}$ and is composed of three swaths containing nine burst each. The 

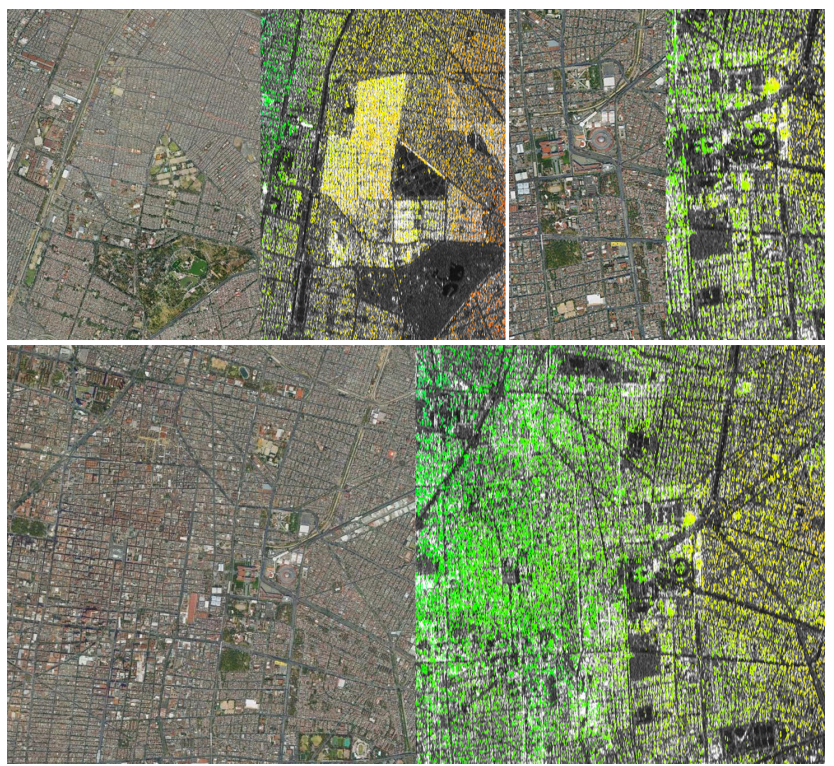

Figure 2. Three examples of the sample density of Cousin Persistent Scatterers (CPSs) achieved in the urban area of the processed burst. Each example shows an orthoimage and the SAR amplitude image of the same area with the CPSs processed with the PSI technique.

results of the PSI processing of one burst (Fig. 1), which encompass a significant portion of Mexico DF, are shown in this paper. The spatial resolution of these images is approximately 3 by $20 \mathrm{~m}$ in range and azimuth, respectively. The area processed cover approximately 80 by $25 \mathrm{~km}$ and a density of $575 \mathrm{CPS} \mathrm{km}^{-2}$ has been achieved (Fig. 2), with a total of 720882 CPSs processed. Sentinel-1 SAR imagery offers wide-area coverage associated to a relatively high spatial resolution, therefore allowing to obtain a comprehensive outlook of the deformation phenomena occurring in wide areas while, at the same time, maintaining the capability to measure individual features such as buildings or infrastructures. It is also important to note that the PSI technique is opportunistic, which means that it is only able to estimate deformation over the available CPSs, i.e. those points where PSI phases maintain good quality over time to get reliable deformation estimates.

Figure 3 shows a deformation map of the burst under study derived from 10 Sentinel-1 images and a total of 45 interferograms. Positive values (blue) indicate displacements towards the SAR, while the negative ones (red) denote displacements away from the SAR sensor. Note that these values refer to the SAR Line-of-Sight (LOS). The map shows a large area affected by subsidence (red) with displacement values of up to $9 \mathrm{~cm}$ occurred during the four months of observations.

The time series of deformation (TS) is one of the most interesting and advanced products derived with the PSI technique. TSs display the deformation history of each CPS over the observed period. Several examples of TS of deformation
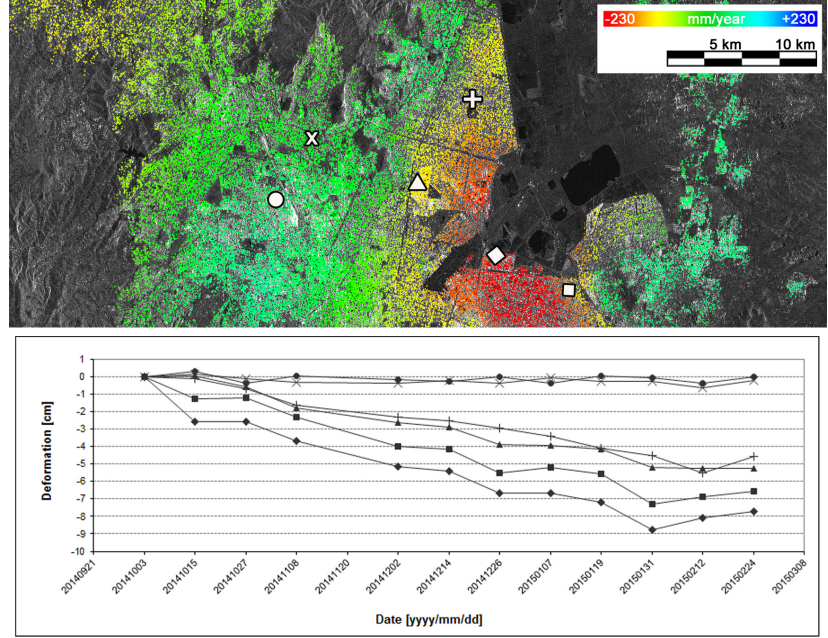

Figure 3. Deformation map (top panel) of the processed burst encompassing a large area of Mexico DF superimposed over a SAR amplitude image, and six examples of time series of deformation (bottom panel) from the same area.

are shown in Fig. 3. These TSs show different behavior; some of them display a stable behaviour, which is related to the green colour in the deformation map, while others show subsidence values of up to $9 \mathrm{~cm}$ which are associated to red in the deformation map.

\section{Conclusions}

The study presented here is the first attempt of the authors to process Sentinel-1 imagery using the PSI technique. A brief description of the processing chain is provided followed by an analysis of the results achieved, i.e. the deformation map and time series of deformation.

The PSI processing chain described in this work was carried out without performing any additional steps at the image processing level. However, the chain employed in this study is reliable to run burst-wise in cases where the coherence is relatively high.

Acknowledgements. This work has been partially funded by the Spanish Ministry of Economy and Competitiveness through the project MIDES "Monitorización y análisis sistemáticos de deformaciones del terreno, estructuras e infraestructuras sobre areas muy extensas" (Ref. CGL2013-43000-P).

\section{References}

Baarda, W.: A Testing Procedure for Use in Geodetic Networks, Rijkscommissie voor Geodesie, Delft, the Netherlands, 1968.

Bell, J. W., Amelung, F., Ferretti, A., Bianchi, M., and Novali, F.: Permanent scatterer InSAR reveals seasonal and longterm aquifer-system response to groundwater pumping 
and artificial recharge, Water Resour. Res., 44, W02407, doi:10.1029/2007WR006152, 2008.

Björck, Å.: Numerical Methods for Least Square Problems, Siam, Philadelphia, PA, USA, 1996.

Bovenga, F., Wasowski, J., Nitti, D. O., Nutricato, R., and Chiaradia, M. T.: Using COSMO/SkyMed X-band and ENVISAT Cband SAR interferometry for landslides analysis, Remote Sens. Environ., 119, 272-285, 2012.

Cigna, F., Osmanoglu, B., Cabral-Cano, E., Dixon, T. H., ÁvilaOlivera, J. A., Garduño-Monroy, V. H., DeMets, C., and Wdowinski, S.: Monitoring land subsidence and its induced geological hazard with Synthetic Aperture Radar Interferometry: A case study in Morelia, Mexico, Remote Sens. Environ., 117, 146-161, 2012.

Colesanti, C., Ferretti, A., Prati, C., and Rocca, F.: Monitoring landslides and tectonic motions with the Permanent Scatterers Technique, Eng. Geol., 68, 3-14, 2003.

Colesanti, C., Le Mouélic, S., Bennani, M., Raucoules, D., Carnec, C., and Ferretti, A.: Detection of mining related ground instabilities using the permanent scatterers technique - a case study in the east of France, Int. J. Remote Sens., 26, 201-207, 2005.

Costantini, M.: A novel phase unwrapping method based on network programming, IEEE T. Geosci. Remote., 36, 813-821, 1998.

Costantini, M., Farina, A., and Zirilli, F.: A fast phase unwrapping algorithm for SAR interferometry, IEEE T. Geosci. Remote, 37 , 452-460, 1999.

Crosetto, M., Biescas, E., Duro, J., Closa, J., and Arnaud, A.: Generation of Advanced ERS and Envisat Interferometric SAR Products Using the Stable Point Network Technique, Photogramm. Eng. Rem. S., 74, 443-450, 2008.

Crosetto, M., Monserrat, O., Cuevas, M., and Crippa, B.: Spaceborne Differential SAR Interferometry: Data Analysis Tools for Deformation Measurement, Remote Sensing, 3, 305-318, 2011.

Crosetto, M., Monserrat, O., Cuevas-González, M., and Devanthéry, N.: Persistent Scatterer Interferometry: a review, ISPRS J. Photogram. Remote Sens., submitted, 2015.

Devanthéry, N., Crosetto, M., Monserrat, O., Cuevas-González, M., and Crippa, B.: An approach to Persistent Scatterer Interferometry, Remote Sensing, 6, 6662-6679, 2014.
Ferretti, A., Prati, C., and Rocca, F.: Nonlinear subsidence rate estimation using permanent scatterers in differential SAR interferometry, IEEE T. Geosci. Remote, 47, 2202-2212, 2000.

Ferretti, A., Prati, C., and Rocca, F.: Permanent scatterers in SAR interferometry, IEEE T. Geosci. Remote, 39, 8-20, 2001.

Förstner, W.: Reliability, gross error detection and self-calibration, ISPRS Commission III Tutorial on Statistical Concepts for Quality Control, ISPRS Int. Arch. Photogramm., 26, 1-34, 1986.

Heleno, S. I. N., Oliveira, L. G. S., Henriques, M. J., Falcão, A. P., Lima, J. N. P., Cooksley, G., Ferretti, A., Fonseca, A. M., LoboFerreira, J. P., and Fonseca, J. F. B. D.: Persistent Scatterers Interferometry detects and measures ground subsidente in Lisbon, Remote Sens. Environ., 115, 2152-2167, 2011.

Hilley, G. E., Bürgmann, R., Ferretti, A., Novali, F., and Rocca, F.: Dynamics of slow-moving landslides from Permanent Scatterer análisis, Science, 304, 1952-1955, 2004.

Jung, H., Kim, S., Jung, H., Min, K., and Won, J.: Satellite observation of coal mining subsidence by permanent scatterer analysis, Eng. Geol., 92, 1-13, 2007.

Meta, A., Mittermayer, J., Prats, P., Scheiber, R., and Steinbrecher, U.: TOPS imaging with TerraSAR-X: Mode design and performance analysis, IEEE T. Geosci. Remote, 48, 759-769, 2010.

Prats-Iraola, P., Scheiber, R., Marotti, L., Wollstadt, S., and Reigber, A.: TOPS interferometry with TerraSAR-X, IEEE T. Geosci. Remote, 50, 3179-3188, 2012.

Stramondo, S., Saroli, M., Tolomei, C., Moro, M., Doumaz, F., Pesci, A., Loddo, F., Baldi, P., and Boschi, E.: Surface movements in Bologna (Po Plain - Italy) detected by multitemporal DInSAR, Remote Sens. Environ., 110, 304-316, 2007.

Tomás, R., Márquez, Y., Lopez-Sanchez, J. M., Delgado, J., Blanco, P., Mallorquí, J. J., Martínez, M., Herrera, M., and Mulas, J.: Mapping ground subsidence induced by aquifer overexploitation using advanced Differential SAR interferometry: Vega Media of the Segura river (SE Spain) case study, Remote Sens. Environ., 98, 269-283, 2005.

Vallone, P., Giammarinaro, M. S., Crosetto, M., Agudo, M., and Biescas, E.: Ground motion phenomena in Caltanissetta (Italy) investigated by InSAR and geological data integration, Eng. Geol., 98, 144-155, 2008. 